\title{
Level of Awareness on the Procurement Law (Ra9184) and its IRR by the Provincial Government of Kalinga Employees
}

\author{
Juan Moshe M. Duyan, John John C. Venus, Karen Razelle M. Duyan
}

Kalinga State University, Philippines

Received: 30 Sep 2020; Received in revised form: 07 Dec 2020; Accepted: 18 Dec 2020; Available online: 31 Dec 2020

(C)2020 The Author(s). Published by Infogain Publication. This is an open access article under the CC BY license

(https://creativecommons.org/licenses/by/4.0/).

\begin{abstract}
The research is conducted to measure the level of awareness on the Procurement Law RA9184 and its IRR by the Provincial Government of Kalinga by seeking to determine the level of awareness on the provision of R.A. 9184 and its IRR as perceived by the two groups of respondents. The researcher used the descriptive survey type of research to gather the data.

The instrument was lifted from the 2014 Extent of Implementation of Government Procurement Reform Act of 2003(R.A.9184) and its IRR in state colleges in the Cordillera Administrative Region by John John Venus and form the "Online Procurement Performance and Compliance Indicators System". Weighted Mean and Ranking is used to determine the obtain level of awareness on the policies and provisions of R.A 9184 and its IRR. The results

Showed that the respondents are very much aware on all areas of the provision of R.A. 9184 and its IRR. The respondents have the highest level of awareness on Procurement by Electronic Means and lowest mean level of awareness on Preparation of Bid Documents. It is then the researcher's recommendation to reinforce the knowledge of the respondents in the provision of R.A. 9184 and its IRR. Researches should also conduct the respondents' best practices for it to serve as basis for other procuring entities in the Province of Kalinga.
\end{abstract}

\section{Keywords- Level of awareness, Procurement Law (RA 9184), IRR, Provincial Government, Kalinga} Employees.

\section{INTRODUCTION}

The Revised Implementing Rules and Regulations, hereinafter called the IRR, is promulgated pursuant to Section 75 of Republic Act No. (R.A.) 9184, otherwise known as the "Government Procurement Reform Act", was enacted on August 3, 2009 for the purpose of prescribing the necessary rules and regulations for the modernization, standardization, and regulation of the procurement activities of the Government of the Philippines (GOP).(RIRR of Republic Act No. (R.A. 9184).

The provisions of this IRR are in line with the commitment of the GOP to promote good governance and its effort to adhere to the principle of transparency, accountability, equity, efficiency, and economy in its procurement process. It is the policy of the GOP that procurement of infrastructure projects, goods and consulting services shall be competitive and transparent, and therefore shall go through public bidding, except as otherwise provided in this IRR under the Alternative modes of procurement.(RIRR of Republic Act No. (R.A.) 9184)

The Legal and regulatory framework is generally the starting point for development of sound governance system. For procurement, such a framework sets the rules and procedures to be observed, and provides the legal 
responsibilities of various participants in the process. It links the procurement process to the overall governance structure and defines the obligations of the government in complying with such requirements. (Asian Development Bank. Philippines Country Procurement Assessment Report. 2012)

The research is conducted to measure the level of awareness on the Procurement Law RA9184 and its IRR by the Provincial Government of Kalinga by seeking to determine the level of awareness on the provision of R.A. 9184 and its IRR as perceived by the two groups of respondents.

The results of this study would guide Administrators/Superiors to undertake constructive measures to solve problems related to the procurement process which will help the employees understand better the procurement process how it works and how it benefits them and their institution; hence, improving their performances, work habits and quality of work which will ultimately lead to a better public services and savings for the government.

The research is focused on the level of awareness on the Procurement Law RA9184 and its IRR by the Provincial Government of Kalinga. It specifically determined the level of awareness on the provision of R.A. 9184 and its IRR as perceived by the respondents.

The result of this study would guide Administrators/Superiors to undertake constructive measures to solve problems related to the procurement process.

\section{Scope and delimitation of the study}

The research is conducted to measure the level of awareness on the Procurement Law RA9184 and its IRR in the Provincial Government of Kalinga by seeking to determine the level of awareness on the provision of R.A. 9184 and its IRR as perceived by the respondents. However it is further delimited to the level of awareness of the Elected officials, BAC Members which includes the Provincial Governor, Vice Governor, 8 provincial Board members, 5 BAC Members, 1 BAC Secretariat and 6 Technical Working Groups and the Chief of Offices and End User.

\section{METHODOLOGY}

The study will be conducted in Provincial Government of Kalinga for the year 2018. The researcher used the descriptive survey type of research to gather data which will describe the level of awareness on the procurement law RA 9184 and it's IRR by the provincial government of Kalinga. The respondents are comprise of 22 Elected officials, BAC Members (with BAC Secretariat and Technical Working Group) of the Provincial Government of Kalinga and 35 Chief of Offices/ End Users. The researcher however was only able to retrieve 57 questionnaires out of the 79 floated because most of the respondents are either on official business or personal leave.

\section{Instrumentation}

The questionnaire will be the main data gathering instrument. Secondary sources was reviewed, and interviews was conducted to cross-check responses. The questionnaire is made up of two parts namely: A - Personal profile of the respondents; B - Questionnaire proper: measuring the Level of awareness of respondents on the provision of R.A. 9184 and its IRR. The A and B part I of instrument was lifted from the 2014 Extent of Implementation of Government Procurement Reform Act of 2003(R.A.9184) and its IRR in state colleges in the Cordillera Administrative Region a research conducted by John John Venus and B part II was lifted from the "Online Procurement Performance and Compliance Indicators System" hence it is deemed valid and reliable.

\section{Data Analysis}

The data was gathered, the researchers tabulated, analyzed and interpreted them. In order for the researchers to give full meaning of the gathered data, the following statistical treatments were utilizing the SPSS were used. The weighted Mean and Ranking. It is used to determine the obtain level of awareness on the policies and provisions of R.A 9184 and its IRR. The Three-Point Likert Scale was used in the interpretation of the result of the study: 


\section{RESULT AND DISCUSSION}

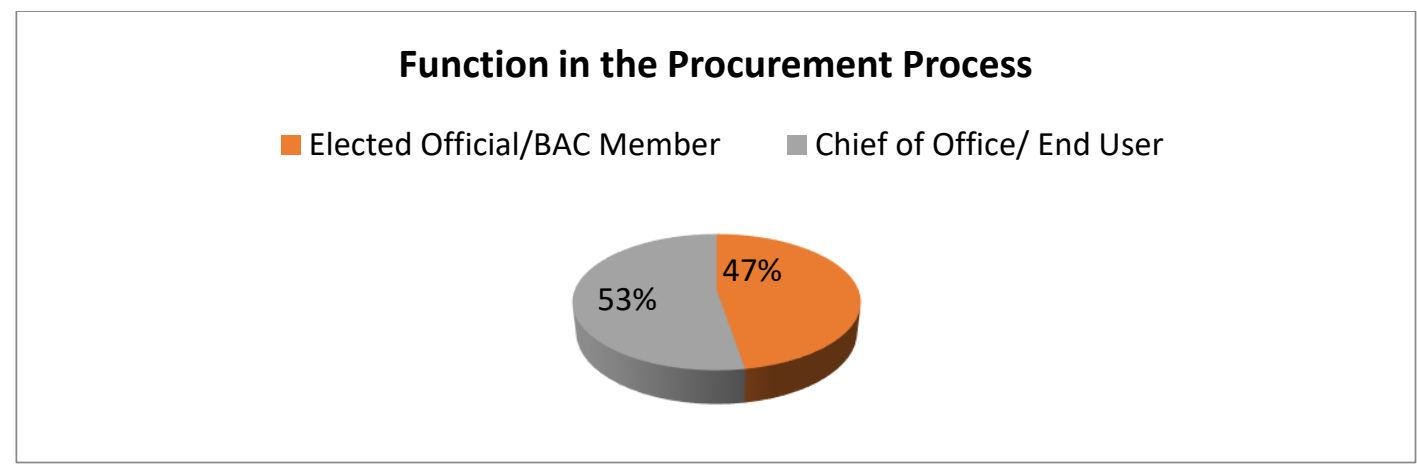

Fig.1: Function of Respondents in the Procurement Process

The figure shows that 53\% of the respondents are elected officals/ BAC members and $47 \%$ are either Chief of Office or end users.

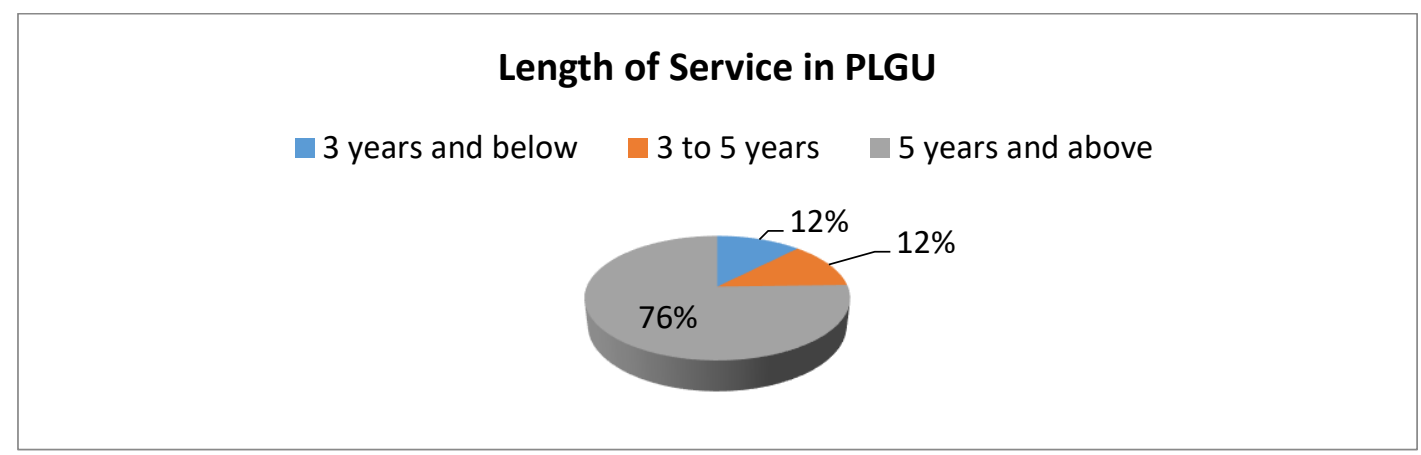

Fig.2: Respondents' Length of Service in the Provincial Local Government Unit of Kalinga

The length of service of the 57 respondents in the Provincial Local Government Unit of Kalinga as shown in Figure 2 reflects that majority or $76 \%$ have been in service for 5 years and more.

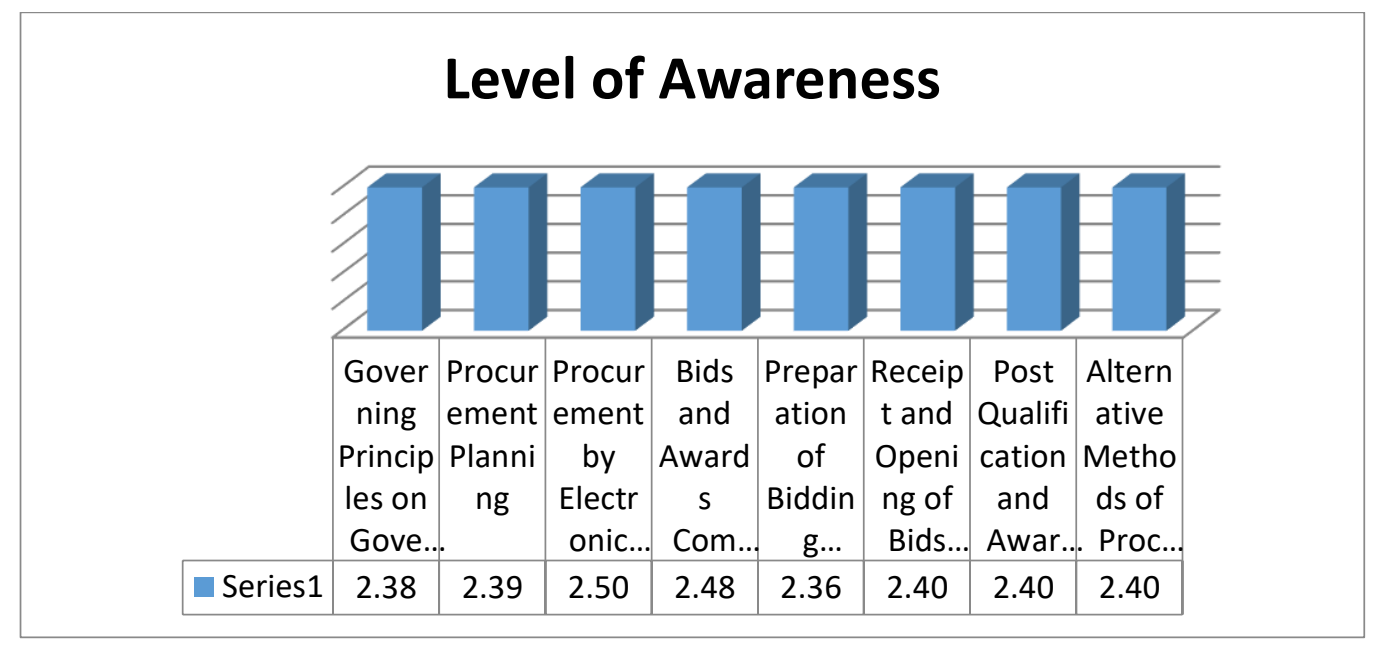

Fig.3: Respondents' Level of Awareness on the awareness on the Procurement Law RA9184 and its IRR of the PLGU Kalinga Employees 
Figure 3 is the mean results on the level of awareness of the respondents. It was found out that they are very much aware on all areas of the provision of R.A. 9184 and its IRR. The respondents have the highest level of awareness on Procurement by Electronic Means with a mean score of 2.5 followed by their awareness on the composition and function of the BIDS and Awards Committee, Receipt and Opening of Bids and Evaluation, Post Qualification and Awards and Alternative Methods of Procurement all have mean score of 2.40. The respondents"' 2.39 mean in level of awareness on the Procurement Planning and 2.38 on the Governing Principles on Government Procurement still signifiy that they are very much aware on the provisions of law and it's IRR. The respondents have the lowest mean level of awareness on Preparation of Bid Documents.
Figures 4 to 11 are the detailed discussion of the major areas in the provision of R.A. 9184 and its IRR.

Governing Principles on Government Procurement include the respondents' awareness that:

1. The BAC maintains transparency in the procurement process.

2. The BAC extends equal opportunity to enable private contracting parties who are eligible and qualified to participate in public bidding.

3. The BAC adopts a system of accountability in the procurement contracts.

4. The BAC streamlines procurement process and in the implementation of awarded contracts to winning bidders.

5. The BAC monitors the procurement process and in the implementation of awarded contracts to winning bidders.

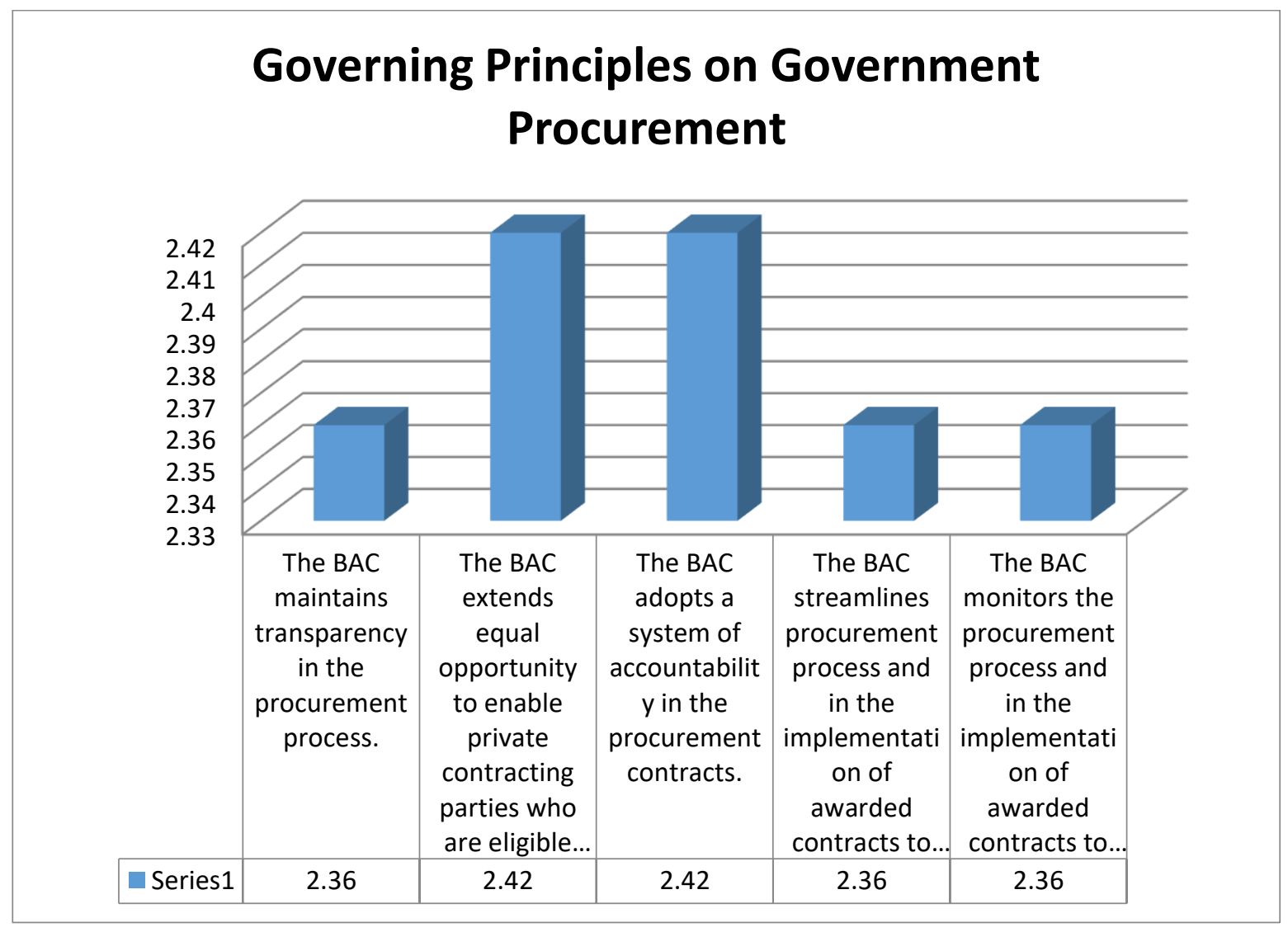

Fig.4: Level of Awareness of the respondents on Governing Principles on Government Procurement

Figure 4 reflects the means of level of awareness on Procurement law by the respondents in terms of the Governing Principles on Government Procurement which exhibits that they are very much aware in all the areas. The graph show that the respondents have highest level of awareness on extending equal opportunity to enable private 
contracting parties to participate in bidding and on adopting accountability in the procurement contracts.

The agencies are now mandated to invite observers in all stages of procurement and observers may report factual anomalies to the proper officials. Also, all procurement opportunities of government are required to be posted in the Government Electronic Procurement System (G-EPS)

The respondent's mean score of 2.36 on maintaining transparency, streamlining of the procurement process and in monitoring the procurement process indicates that they are very much aware of this mandate.

The area of Procurement Planning includes the respondents' awareness that:
1. Procurement is within the approved budget of the Province.

2. Procurement is undertaken in accordance with the approved APP of the provincial government.

3. The end-user units prepare their respective Project Procurement Management Plan (PPMP)for:

a. Different programs and activities

b. Different projects intended for state colleges

4. Updates the individual PPMPs and consolidates APP for each procuring entity, is undertaken every six (6) months or as often as may be required.

5. The $\mathrm{ABC}$ must be consistent with the appropriation for the project as authorized in the GAA.

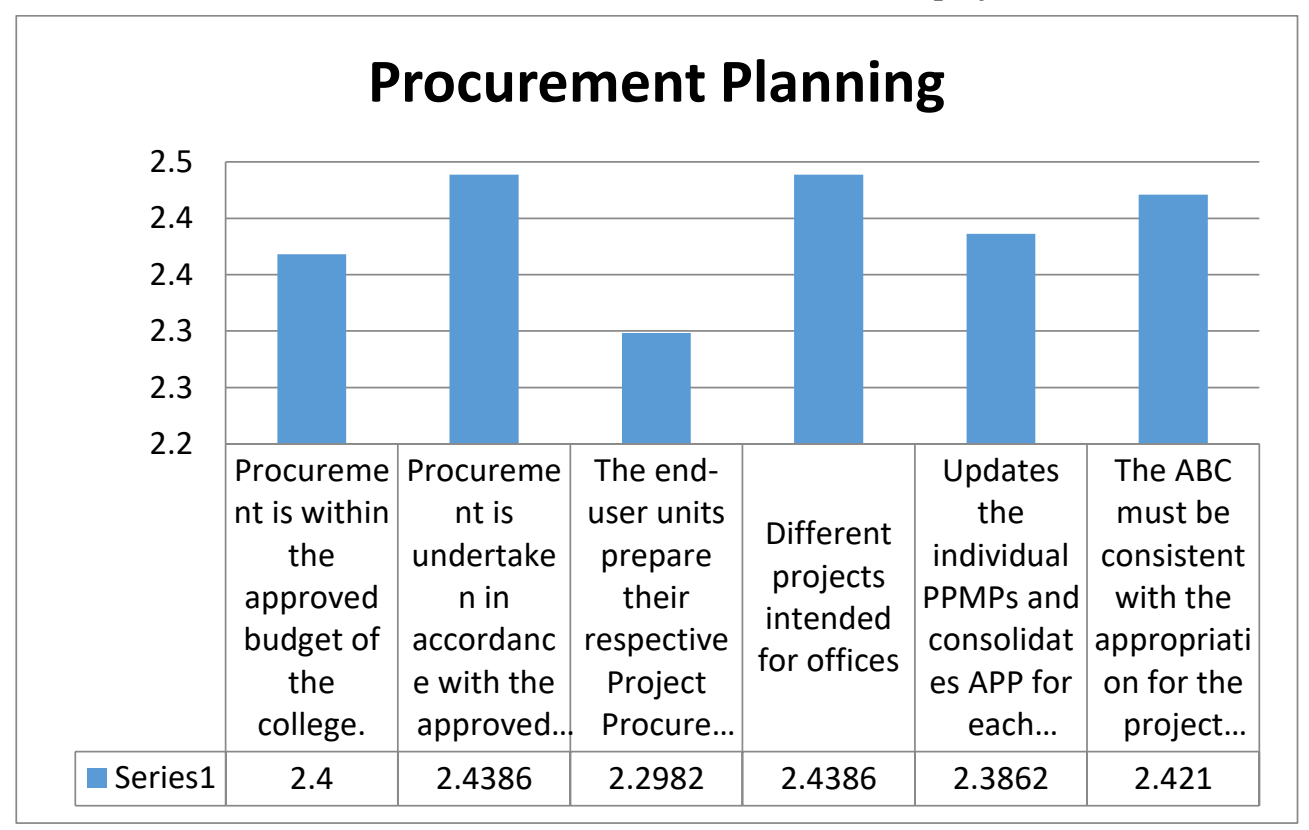

Fig.5: Level of Awareness of the respondents on Procurement Planning

As seen in Figure 5 the respondents are very much aware in all areas of Procurement Planning. Their mean score of 2.43 shows that the respondents are very much aware that procurement should be undertaken in accordance with the approved APP of the provincial government and that The end user should prepare the PPMP for different projects intended for the office. They however got the lowest awareness on the fact that the end user should prepare the PPMP for different programs and activities with only 2.29 mean score or much aware.

The aspect of Procurement by Electronic Means include the respondents' awareness that:
1. Procuring institution is duly registered with the PhilGEPS

2. Procuring Entities shall post in the PhilGEPS bulletin board all:
a. Procurement opportunities
b. Results of bidding
c. Related information

3. The PhilGEPS shall have a centralized electronic database of stakeholders.

4. Stakeholders are issued with a digital certificate from the government-accredited certification authority to participate in the procurement activities of the PhilGEPS. 


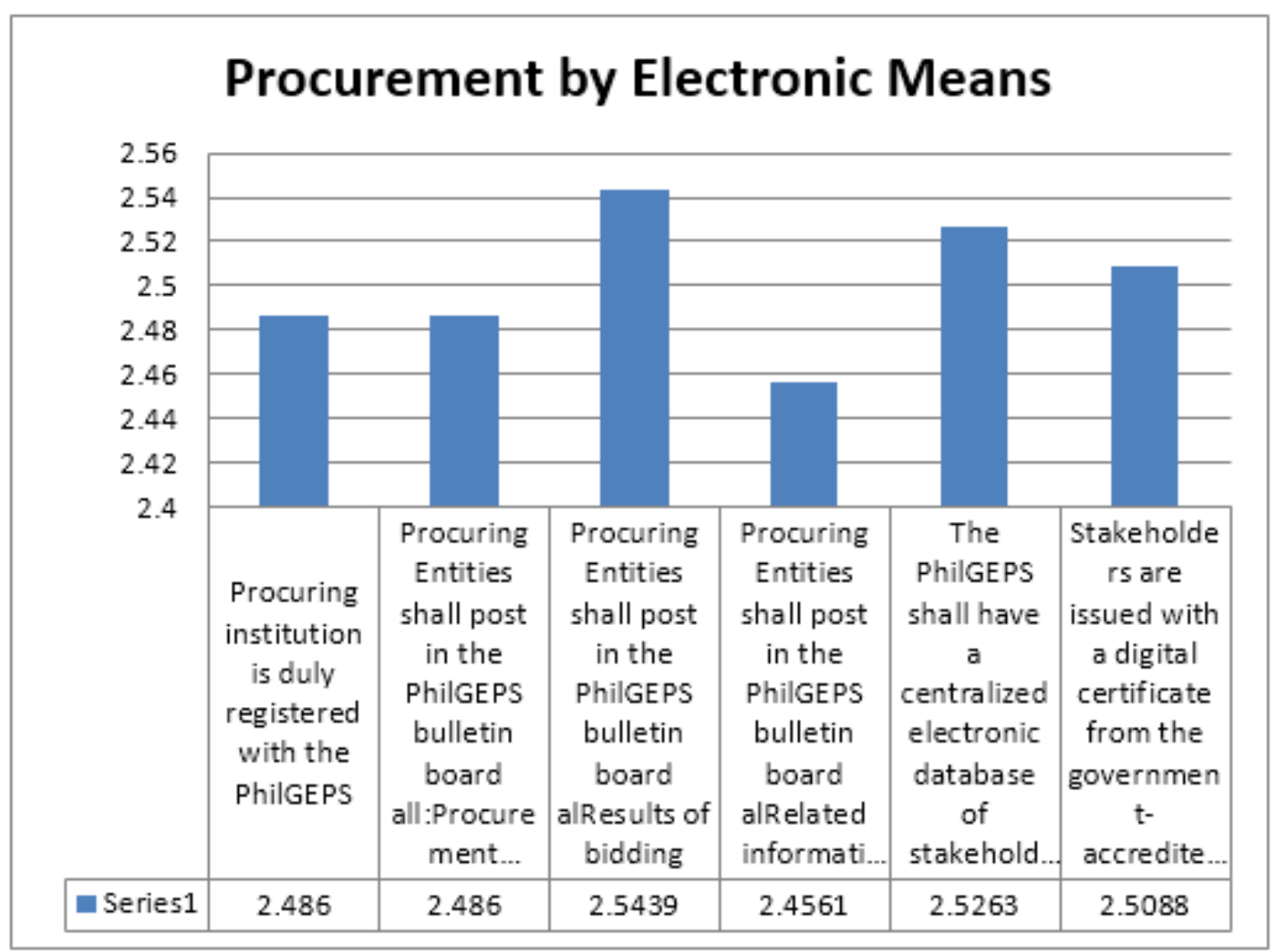

Fig.6: Level of Awareness of the respondents on Procurement by Electronic Means

In terms of the respondents' awareness on procurement by electronic means, the respondents' awareness level on posting in the PhilGeps bulletin, all the results of bidding got the highest mean of 2.54 and the lowest mean score of 2.4562 on posting in the PhilGeps of all related information. When asked why, some of the respondents reasoned out that they thought only the procurement opportunities and results are being required.

Sections 23.4 and 24.4.3 allows the BAC of a procuring entity to "maintain a registry system using the PhilGEPS or its own manual or electronic system that allows submission and/or recording of eligibility requirements simultaneously with registration." However, Prospective bidders not included in the registry system should not be precluded from participating in any procurement opportunity. To find out the depth of their awareness on this, the researcher asked some of the respondents follow up questions and their answer are as follows:
The aspect of Bids and Awards Committee include the respondents' awareness that:

1. Procuring entities has a single BAC composition.

2. Procuring institution designates at least five (5) but not more than seven (7) members to the BAC

3. Procuring institution has a Secretariat which serves as the main support unit of the BAC.

4. The BAC during procurement process invites a representative from the $\mathrm{COA}$ and at least two observers.

5. The BAC during procurement process invites a representative from the $\mathrm{COA}$ and at least two observers.

6. The BAC during procurement process invites a representative from the $\mathrm{COA}$ and at least two observers. 


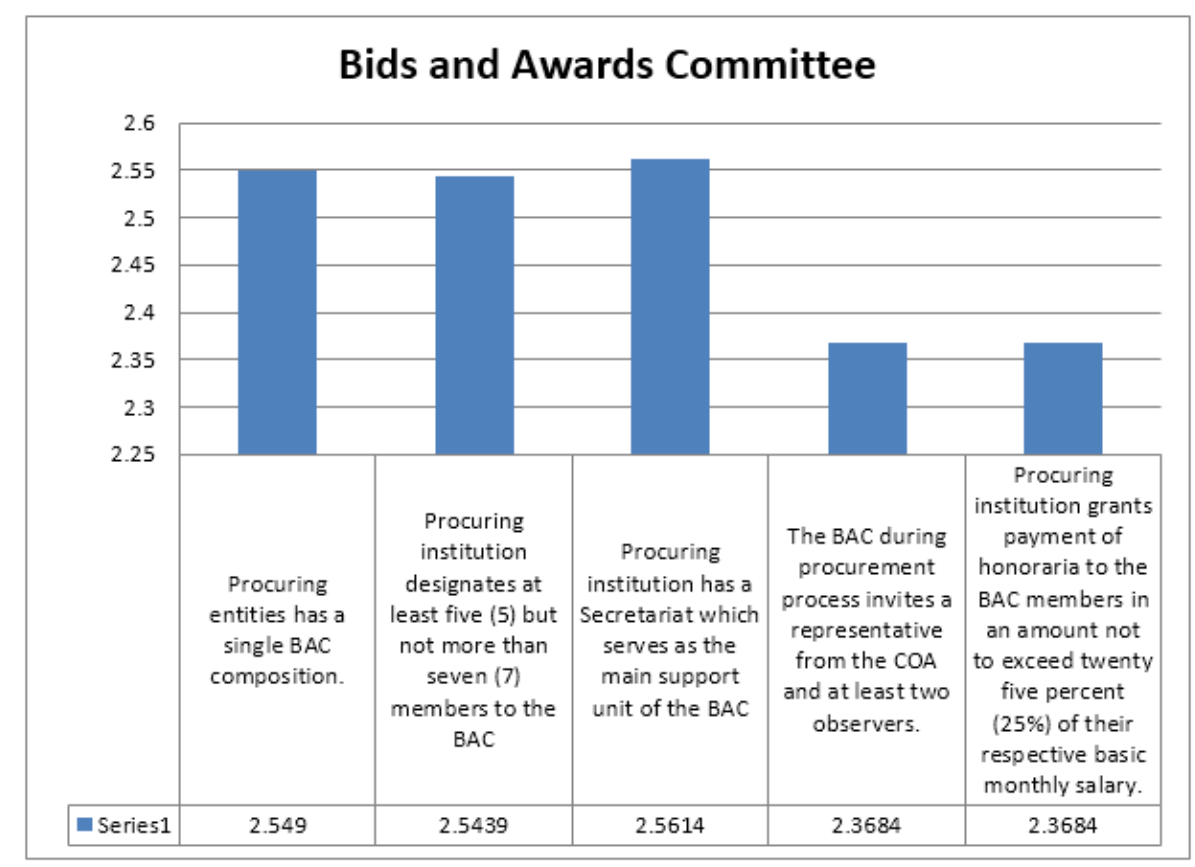

Fig.7: Level of Awareness of the respondents on Bids and Awards Committee

Figure 7 shows that the respondents have the highest mean score of 2.56 or an equivalent of very much aware awareness on the rule that procuring institution should have a secretariat that serves as the main support of BAC

They got the lowest mean score of 2.3684 but still very much aware both on their awareness that BAC during procurement process should invite a representative from COA and at least two observers and on their awareness that they can grant honoraria to members in an amount not to exceed $25 \%$ of their basic monthly salary.

The law provides that the $\mathrm{BAC}$ shall, in all stages of the procurement process, invite observers to sit in its proceedings.

It also provides that the BAC shall, in all stages of the procurement process, invite observers to sit in its proceedings.
The aspect on Preparation of Bidding Documents And invitation To Bid include the respondents' awareness that:

Bidding Documents prepared by the procuring entity following the Government Procurement Policy Board(GPPB)

1. Brand names is not allowed

2. Bid/Request for Expression of Interest is:

a. Advertised at least once in one (1) newspaper of general nationwide circulation.

b. Posted continuously in the PhilGEPS.

3. Contracts to be bid with an approved budget of One Million Pesos (P1,000,000.00) or more, the BAC shall convene at least one (1) pre-bid conference 


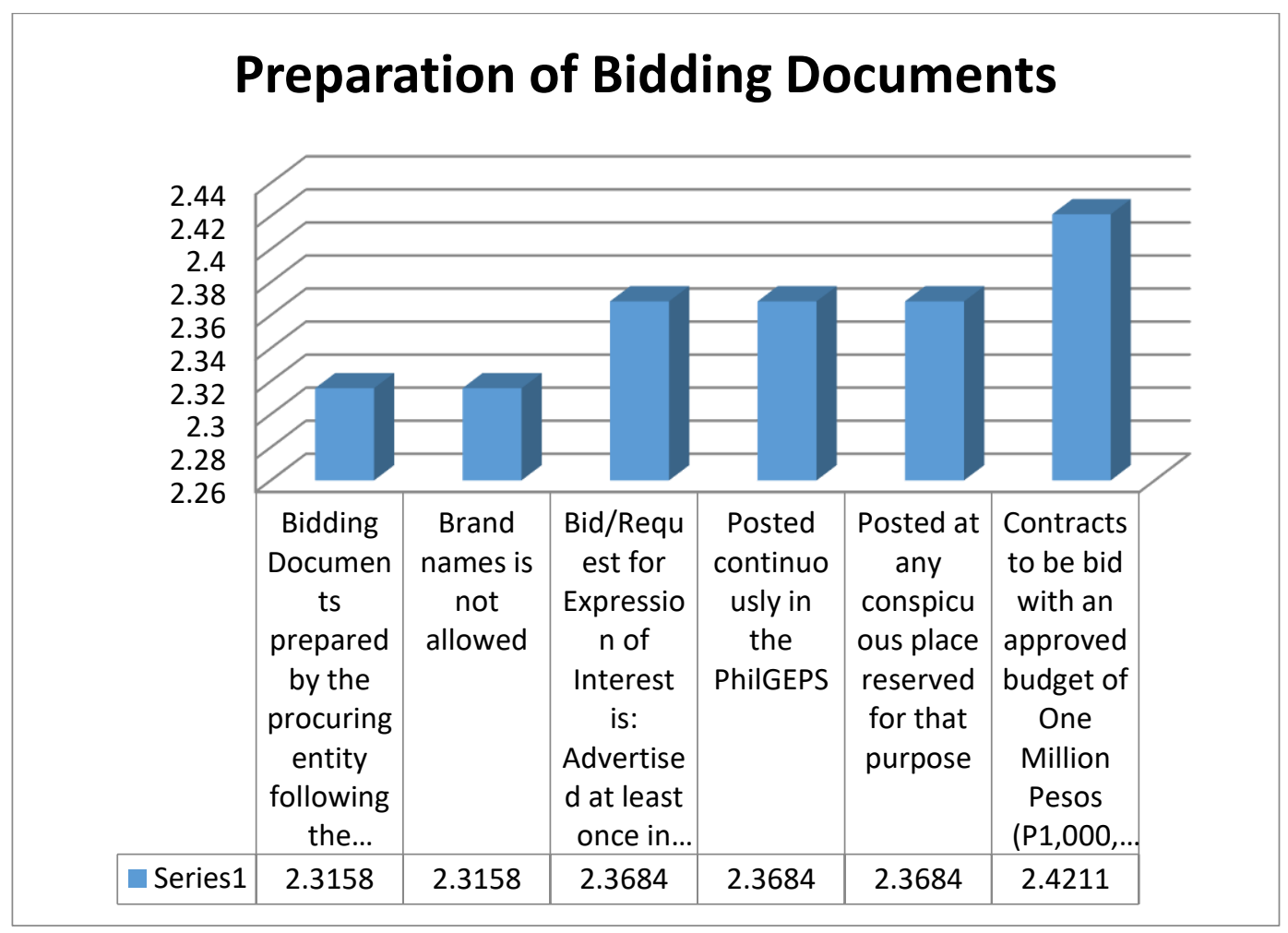

Fig.8: Level of Awareness of the respondents on Preparation of Bidding Documents And invitation To Bid

It is reflected in Figure 8 that the respondents are very much aware that brand names are not allowed during the preparation of bidding documents and invitation. When asked, Should reference to brand names still not be allowed even if such brand name provides for a lower cost and/or better quality? One of the respondent answered, the IRR provides that specifications for the procurement of goods shall be based on relevant characteristics and/or performance requirements. Reference to brand names shall not be allowed even if the cost is lower. The specifications should be properly prepared by the agency in order to get the desired quality and avoid obtaining materials of inferior quality.
The aspect on Receipt and Opening of Bids And Bid Evaluation include the respondents' awareness that:

Bids, including the eligibility requirements, submitted after the deadline shall not be accepted by the BAC.

1. All bids shall be accompanied by a bid security.

2. Bidders submits their bids in two (2) separate envelopes which includes:

a. Technical component of the bid.

b. The financial component of the bid.

3. The BAC opens the bids immediately after the deadline for the submission and receipt of bids.

4. Approve Budget of the Contract must be the upper limit or ceiling for acceptable bid prices 


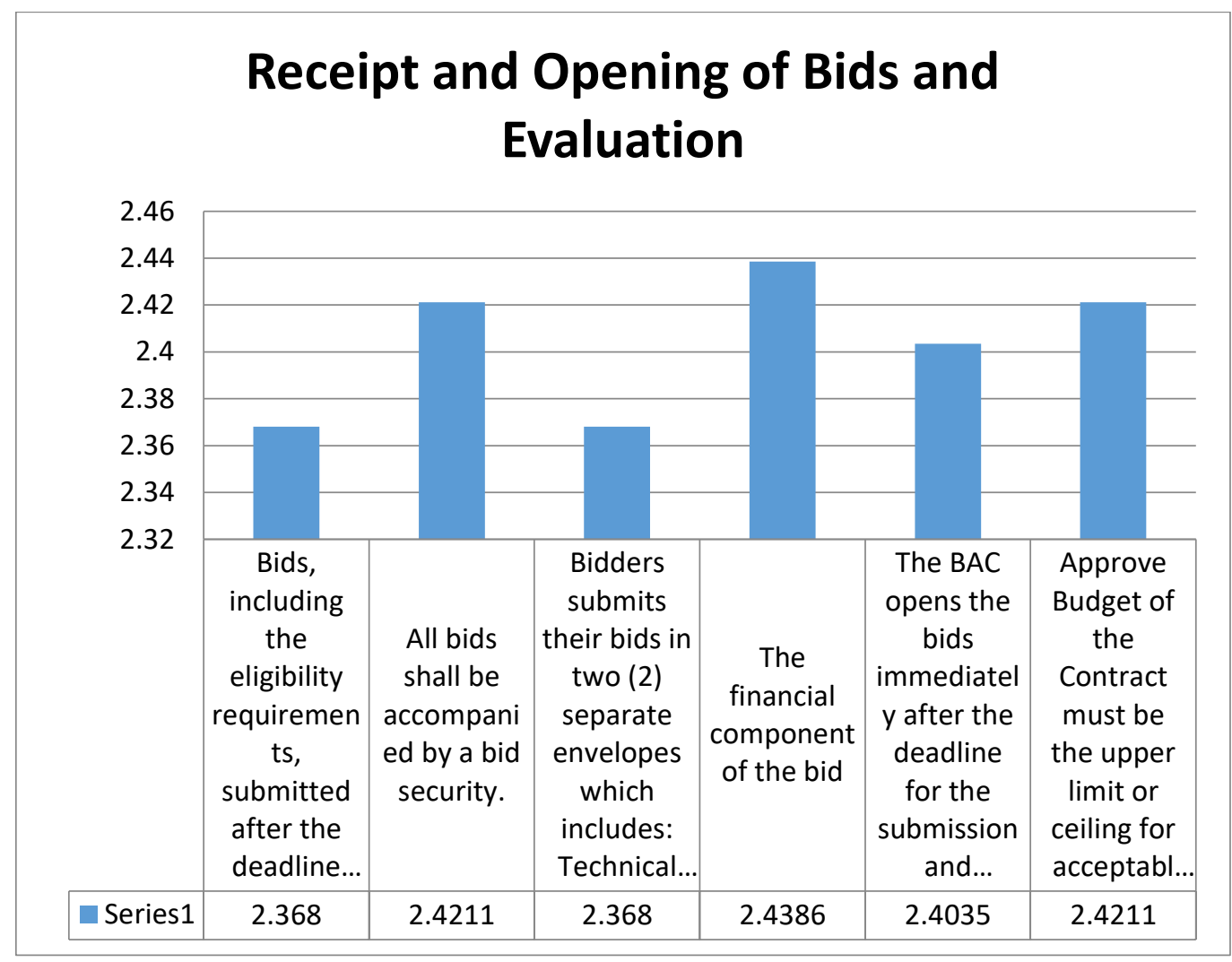

Fig.9: Level of Awareness of the respondents on Receipt and Opening of Bids and Bid Evaluation

In the Receipt and opening of Bids and Evaluation, as shown in Figure 9, the respondents got the highest mean score of 2.4386 or very much aware which means that they are very much aware that bidders are required to submit their bid in 2 separate envelope which include the financial component of bids. They are very much aware also that it should also include the technical component of the bid but in the mean score they only got 2.368 .

The aspect on Post-Qualification and award, Implementation And Termination of The Contract include the respondents' awareness that:

1. The Lowest Calculated Bid undergo postqualification:

a. To determine whether the bidder concerned complies with the bid requirements.

b. Is responsive to all bid requirements and conditions

2. BAC declares the bidding a failure when no bids are received.
3. A single calculated/rated and responsive bid shall be considered for award if it falls under any of the following circumstances:

a. If after advertisement, only one prospective bidder submits an LOI and it meets the eligibility requirement

b. If after advertisement, more than one prospective bidder submits an LOI but only one bidder meets the eligibility requirements.

c. If after the eligibility check, more than one bidder meets the eligibility requirements, but only one bidder submits to bid, and its bid is found to be responsive to the bidding requirement.

4. Procuring Entity reserves the right to reject any and all bids, declare a failure of bidding. 


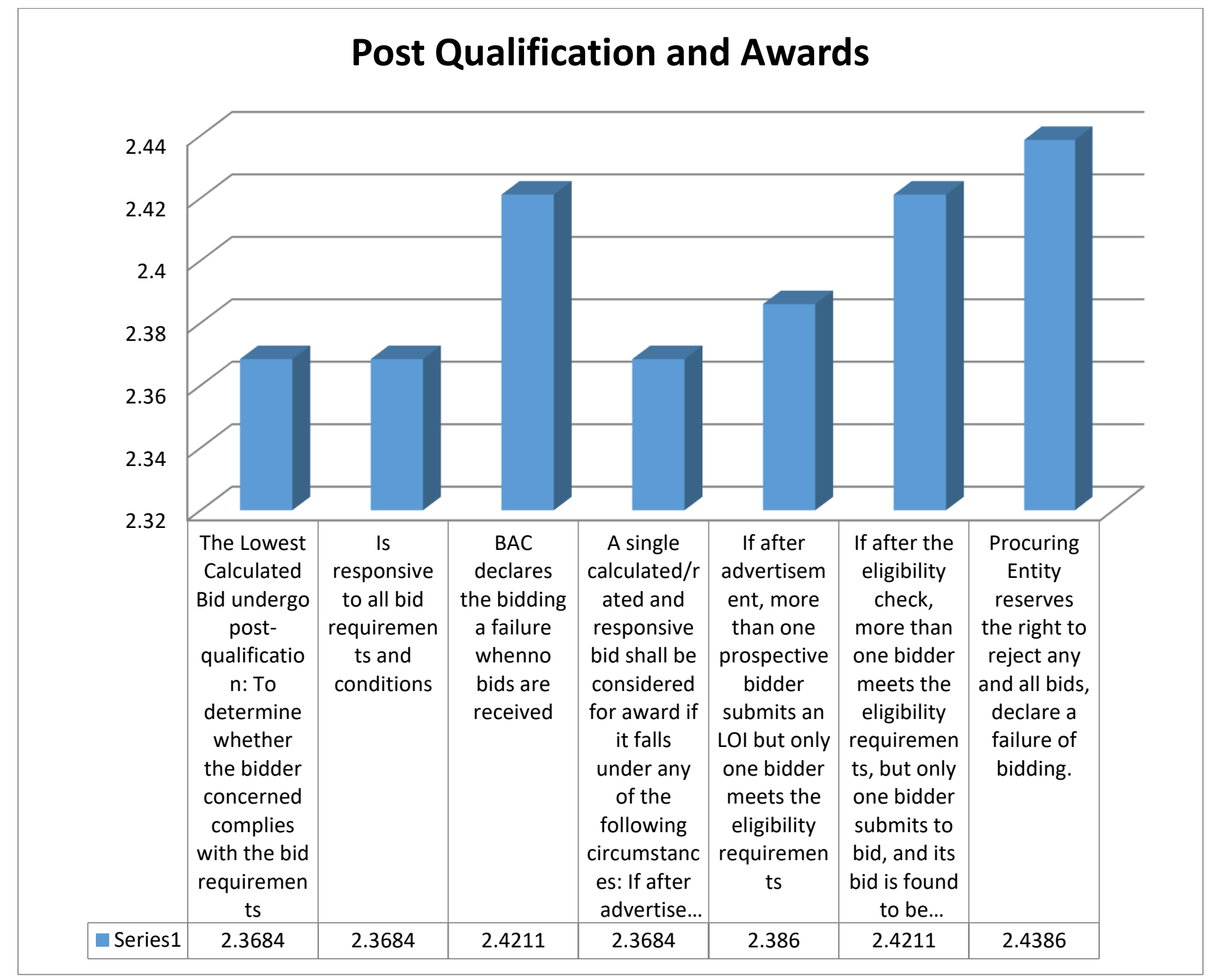

Fig.10: Level of Awareness of the respondents on Post-Qualification and award, Implementation and Termination of the Contract

Figure 10 shows that the respondents are very much aware with a mean score of 2.421 that BAC declares a bidding failure when no bids are received. This level of awareness is evidenced by an interview with one of the Chief office who said that In case there is a failure of bidding, an agency can undertake the works by administration only if there is imminent danger to life or property or when time is of the essence or when immediate action is necessary to restore vital public services.

The aspect on Alternative Methods Of Procurement include the respondents' awareness that:
1. Procuring institution resorts to alternative methods in order to promote economy and efficiency.

2. Limited Source Bidding involves direct invitation to bid of goods and consulting services.

3. Direct Contracting is allowed when the supplier is asked to submit a price quotation or a proforma invoice together with the conditions of sale.

4. Repeat Order is used to replenish goods procured under a contract previously awarded through Competitive Bidding 
5. Repeat Order is used to replenish goods procured under a contract previously awarded through Competitive Bidding

6. Shopping is allowed the procuring institution simply requests for the submission of price quotations suppliers of known qualifications

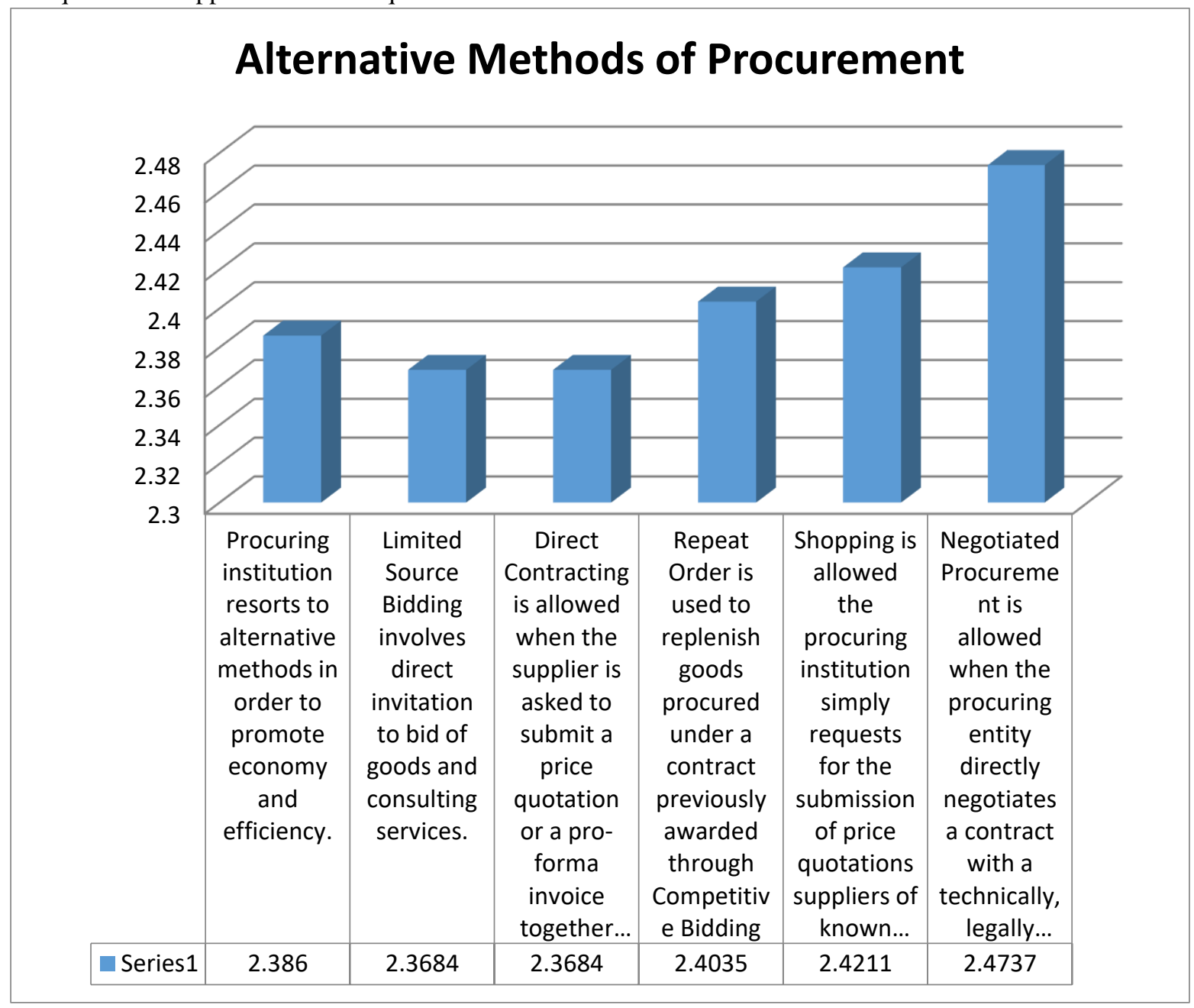

Fig.11: Level of Awareness of the respondents Alternative Methods of Procurement

The awareness of the respondents that allowance of negotiated procurement is allowed when the procuring entity directly negotiates a contract with a technically, legally and financially capable supplier, contractor or consultant got the highest mean of 2.473 or very much aware. The law mandates agencies to procure common used supplies and materials in the Procurement Service (PS). To test their knowledge on this, the researcher asked one of the respondents a scenario and how are they able to address it.
7. Negotiated Procurement is allowed when the procuring entity directly negotiates a contract with a technically, legally and financially capable supplier, contractor or consultant 
Researcher: On negotiated contracts for LGUs, even if all requirements are satisfied, is the Sangguniang Panlalawigan/ Panglungsod's approval still required? Or is the approval of the procuring entity enough?

Respondent: Even if there is a resolution of the PLGU, but there is a requirement that the Saggunian needs to approve then we have to follow it.

Researcher: Some say that negotiated procurements may expose the members to corruption in procurement process, what do you think is the solution to prevent it?

Respondent: Negotiated procurements are allowed to be conducted but approval of the head of the procuring entity if there are justifiable reasons which you can find in the IRR/R.A. 9184.

\section{CONCLUSION}

The mean results on the level of awareness of the respondents shows that the respondents are very much aware on all areas of the provision of R.A. 9184 and its IRR. The respondents have the highest level of awareness on Procurement by Electronic Means with a mean score of 2.5 followed by their awareness on the composition and function of the BIDS and Awards Committee, Receipt and Opening of Bids and Evaluation, Post Qualification and Awards and Alternative Methods of Procurement all have mean score of 2.40. The respondents" 2.39 mean in level of awareness on the Procurement Planning and 2.38 on the Governing Principles on Government Procurement still signify that they are very much aware on the provisions of law and it's IRR. The respondents have the lowest mean level of awareness on Preparation of Bid Documents.

\section{RECOMMENDATIONS}

It is the researcher's recommendation to reinforce the knowledge of the respondents in the provision of R.A. 9184 and its IRR. Further researches on Provincial Local Government of Kalinga should be conducted to find out their best practices and to serve as basis for other procuring entities in the Province of Kalinga.

\section{REFERENCES}

[1] Adjei, A. B. (2006). Purchasing and supply: A Competitive tool to strategic development. Paper presented at the seminar of Takoradi Polytechnic Chapter of the Purchasing and Supply Students Association of Ghana, Takoradi, Ghana.

[2] Asian Development Bank. Procurement Guidelines. Mandaluyong City, Philippines: Asian Development Bank, 2015.

[3] Baily, P. , David F. , Barry, C. , Jossop, D. \& Jones, D. (2005). Procurement Principles and Management. (9th ed). Person Education Limited, England.

[4] Burt, N. D. , Dobler, W. D. \& Starling, L. S. (2006). World Class Supply Management. (7th ed.) New Delhi: Tata McGraw-Hill.

[5] Dmitri, N. et. al. Handbook of Procurement. Cambrige University Press. 2006

[6] Gelderman, C. J., Ghijsen P. W .Th. \& Brugman, J. M. (2006). Public procurement and EU tendering directives explaining non-compliance. The International Journal of Public Sector Management.

[7] Handbook on Philippine Government Procurement, 6th ed. Revised Implementing Rules and Regulations, Republic Act 9184.2012

[8] Kusi, Lawrence Y. Assessment of Public Procurement Policy Implementation in the Educational Sector (A Case Study of Takoradi Polytechnic). International Journal of Academic Research in Business and Social Sciences. October 2014, Vol4, No. 10 ISSN: 2222-6990

[9] United Nations Environment Programme Sustainable Public Procurement: A Global Review Final Report. United Nations Environment Programme (UNEP). 2013 